\title{
WORK INTEGRATED LEARNING BENEFITS FOR STUDENT CAREER PROSPECTS - MIXED MODE ANALYSIS
}

\author{
C. M. Govender* \\ e-mail: cookig@uj.ac.za
}

\author{
M. Wait* \\ e-mail: mwait@uj.ac.za
}

*Department of Marketing Management

University of Johannesburg

Johannesburg, South Africa

\section{ABSTRACT}

Work integrated learning (WIL) aims to strategically inspire students to embrace prospective future careers, thereby contributing to economic innovation and growth. Higher Education is mandated to integrate WIL into curricula and qualifications in order to promote student career development. This is an invaluable opportunity for academics to not only integrate theory and practice, but to expose graduates-to-be to the world of work and assess their experiential learning. Most academics seem to shy away from WIL implementation due to perceived increase in workload, denying themselves and their students the benefits of WIL, especially for student career prospects.

This empirical article reports on a transdisciplinary exploration into the benefits of two discipline-specific WIL projects using a mixed model analysis approach. A comparative, triangulated study of the Marketing qualitative and Human Resource quantitative data reveals that the students enjoy their WIL experience, gain additional knowledge and skills, and are exposed to various career opportunities.

Key words: Work integrated learning; Higher Education; transdisciplinary; HRM; Marketing; career prospects; placement; skills, triangulation.

\section{INTRODUCTION}

Employers demand that higher educational institutions should provide a strong knowledge base to their graduates, and are especially concerned if these graduates are not equipped to apply that knowledge at work. A growing number of reports argue that a strong disciplinary knowledge base does not necessarily guarantee a graduate a job. One technique that could improve students' work readiness and ability to transfer theoretical knowledge into the practical implementation, is work integrated learning or WIL (Freudenberg, Brimble and Vyvyan 2010, 43). 
Furthermore, classroom-based instruction alone does not produce future-fit graduates. The role of WIL is to encourage learning for performance. This is essential in the development of the desired graduate profile. The competency profile of a graduate should include disciplinespecific knowledge, skills and attitudes, as well as workplace generic cognitive, behavioural and technical skills and attributes (Powell, Tindal and Millwood 2008; Coll and Zegwaard 2006; Ishisaka et al. 2004).

WIL and work-based learning are gaining momentum within tertiary institutions, including in South Africa (SA). There are definite academic, personal, career and work ethic benefits, and WIL promotes partnerships with business, industry and government to improve economic growth for the country (Matoti, Junqueira and Odora 2011). With nearly 70 per cent of SA's population of 50 million people under the age of 35, Higher Education has to play its role in the process of preparing future-fit graduates to contribute to the growth of the economic sector. Over 11 million employment opportunities are required to reduce South Africa's unemployment rate from 27 per cent in 2011 to 6 per cent by 2030 (South Africa 2011).

The gap in the literature indicates limited empirical research on what the benefits of WIL projects are, whether self-placement is successful, and whether students perceive WIL organisations as promoting their career prospects. This empirical article presents the findings of a transdisciplinary, mixed methods comparative study (Harrison and Reilly 2011) on the benefits of the implementation of WIL in Higher Education. The three research objectives of this article are as follows:

1. To identify whether the WIL experience benefits students.

2. To determine whether self-placement is a rewarding experience for students.

3. To determine whether WIL provides career prospects for students.

The scope of this study consists of dissecting, inspecting and integrating the results of discipline-specific WIL projects in the Marketing and Human Resource Management (HRM) Diploma qualifications. A comparison of the qualitative Marketing and quantitative HRM data was undertaken using a mixed mode research analysis design. This article offers contributions on the theoretical, practical and research levels as follows:

- Theoretical level - adds to the body of knowledge on WIL, especially in African Higher Education.

- $\quad$ Practical level - provides WIL stakeholders (educators, students, business, government) 
with strategies for benefiting from WIL in the use of the self-placement technique and in fostering career prospects.

- Research level - these transdisciplinary, comparative, triangulated conclusions of independent qualitative and quantitative research present a mixed mode analysis in a mixed methods research design that contributes to future research methodological designs.

As background to the article, current trends regarding the benefits of WIL to students, WIL placement methods and WIL and career prospects, are presented in the literature review section. The mixed method research with a triangulated, mixed mode analysis design is described in the methodology section thereafter. The findings of the independent qualitative and quantitative studies are presented in the results section and a triangulation of the findings is presented in the discussion section. The article ends with the conclusion section to summarise the article discussion and to make recommendations for future research.

\section{LITERATURE REVIEW}

Work integrated learning makes Higher Education meaningful for students by personalising their learning, enhancing their awareness of the work relationship, enhancing work-related learning, and encouraging personal aspiration (Mcllveen 2011). This section deals with the student benefits for WIL, WIL placement and career prospects from WIL.

\section{WIL benefits for students}

WIL forces students to be productive and to do real work that translates into social and economic values. There are measurable benefits to students, the employer, the community, and to the educator (McLennan and Keating 2008). When student learning from real-life situations is effectively and authentically assessed by educators, the benefits escalate to the creation of value-adding and character-building of future-fit graduates, ready for the workplace. WIL benefits for students abound, for example, development in these skills: communication, interpersonal relations, technology, writing, punctuality, attendance, team work, leadership, career development, observing theory in practice, putting theory into practice, awareness of workplace culture, meeting workplace expectations; opportunity to develop a range of personal attributes, coping in a rapidly changing world of work, enhanced employment prospects, developing career strategies, developing interactive attributes, and building a network of contacts (McLennan and Keating 2008; Orrell 2004; Cooper, Orrell and Bowden 2010).

WIL projects are implemented to develop student competencies and studies indicate 
substantial personal development by students who participate in such projects. WIL projects have also demonstrated increases in job knowledge and skills, and lead to an improvement of attitudes and behaviours towards work readiness. WIL projects have several positive effects on student learning, such as the identification of theoretical concepts taught in class, putting theory into practice, appreciating that academic success is not the only attribute for career success, and development of communicative abilities (Freudenberg, Brimble and Vyvyan 2010, 44). Valkanos $(2007,22)$ states that the focusing of structured experiences outside of the classroom encourages team spirit, develops cooperation, and improves the decision-making processes of dealing with problems arising at work. Such techniques help students to develop effective communication, problem-solving and decision-making skills.

Students could also benefit from possible financial gains if organisations pay students for their efforts, or they generate income as a result of their WIL experience. The skills and rewards gained from the development of a portfolio of evidence (POE) on work experiences are benefits to students, lecturers and business if it is an authentic account and reflection of the WIL experience. Further benefits include increased employment prospects, the potential to negotiate higher salary packages, development of career strategies, and building networks and contacts (McLennan and Keating 2008). Empirical evidence on the benefits of discipline-specific WIL projects and models, such as in the Marketing field, incorporating the collaboration of all stakeholders for the benefit of the students, is absent. In fact, WIL is often reduced to case studies and industry guest speakers only (Wait 2014, 1680).

The research into the effectiveness of WIL is scarce. Aldridge et al. (2015) mentions that the problem with WIL is that its benefits are undoubted, but difficult to substantiate. The informal and anecdotal evidence in favour of WIL is overwhelming, but the hurdles in the way of proper research into the question need to be overcome. Aldridge et al. (2015) states that WIL principles are not being empirically tested in any rigorous way. This article reports on the empirical studies conducted to measure the benefits of WIL and experiential learning to undergraduate students in an African context.

\section{WIL placement}

Students view work-integrated learning (WIL) placements as the most significant influence on their future career (Gribble et al. 2014). Securing a placement in the workplace, even in developing countries where there are opportunities for tax rebates and skills levy paybacks, can be complex and frustrating. Betts $(2009,100)$ argues that since many companies will not even consider hiring graduates who do not have experience in their field, why should they consider 
undergraduate students?

Stakeholders often ponder if WIL placement is a strength and an opportunity, or a challenge and threat to students and the WIL project? Ideally industry, business and government should be forthcoming, available and accessible; approaching educators and students with offers of workplace placement for experiential learning (Brundiers, Wiek and Redman 2010). Workplace learning units must take responsibility for accepting and placing students into their organisation. HRD (Human Resource Development) managers must especially ensure that there are appropriate standards in supervision of students and that placements are in appropriate contexts so that students and the organisation are able to achieve their goals (McLennan and Keating 2008).

In most WIL projects, the educator controls all interaction between the organisation and the students, including student placements, site visits, ongoing monitoring of student work and progress, and assessment of student learning and performance occurs during the placement (Holdsworth, Watty and Davies 2009, 7). Govender and Taylor (2015) and Walmsley, Thomas and Jameson (2006) propose student self-placement, instead of educator, business or government placement of the student, for an effective and efficient WIL model implementation, as well as tremendous benefits for student experiential learning. The emphasis is on selfplacement as it benefits the student in that s/he must think about, plan, and confidently approach an organisation to request, secure, confirm and complete their WIL placement.

This article reports on the investigation into the benefits and rewards of WIL selfplacement in a cosmopolitan, African city environment.

\section{WIL and career prospects}

The skills required for entry-level workplace practice are indeed not only learnt in the lecture room through cognitive processes, but also through exploring a combination of cultural competence, critical thinking and intellectual reflection that occur in any authentic globalised environment (Gribble et al. 2014; Gamble, Patrick and Peach 2010). However, on the other hand, qualifications that are too vocationally focused may result in losing sight of the academic side of education. It is recognised that students must be equipped with skills that will support them in finding meaningful employment, but education is about more than getting employment. WIL programmes should allow the student to be involved in critical thinking and transformative learning. There is a recognised tension between academic goals and industry productivity; education must remain the overriding principle in any WIL programme (Coll 2007, 137).

The call is for organisations to support WIL projects, establish career paths for 
undergraduates, highlight relevant knowledge transfer, and enter into longterm employment relationships with students entering the marketplace (Reiche, Harzing and Kraimer 2009). Together with universities, colleges and other tertiary institutions, workplace managers should be preparing undergraduate students for their careers through experiential learning and entrepreneurship education (Cooper, Bottomley and Gordon 2004; Cooper, Orrell and Bowden 2010).

There is a positive correlation between the WIL student's social ties, their perceived fit with the organisation to their learning during the WIL experience, and their perceived career prospects in the organisation. Students who hold positive perceived career prospects are more likely to be employed and retained by the organisation (Reiche, Kraimer and Harzing 2011). This article reports on the investigation into whether students consider the organisations they gained their WIL experience from as potential organisations for future career prospects.

\section{RESEARCH METHODOLOGY}

In order to present the authenticity of the original research designs, the qualitative Marketing research design is described first, followed by a description of the quantitative HRM research method. The context is that two independent researchers working independently of each other, in two different campuses of the same university, conducted independent studies on a similar group of students. The theoretical framework underpinning this study is complex yet simple: a mixed model analysis allows researchers to take a parallel and triangulated view of two different methodologies and results around a common theme and/or phenomenon (Leech and Onwuegbuzie 2007; Harrison and Reilly 2011).

This article adopts a mixed mode analysis embedded in a mixed methods research design, otherwise known as a hybrid design (Harrison and Reilly 2011, 19), where the discussion section of this article triangulates the significant findings of two independent qualitative and quantitative studies. A triangulated approach (Leech and Onwuegbuzie 2007; Saunders, Lewis and Thornhill 2007) allows researchers to be grounded by a post-positivist (Zammito 2004; Hamlin 2015) ontology (nature of reality) and epistemology (nature of knowledge). In order to achieve the research objectives as well as infer interpretations and derive meaning from the results of similar research that measures the impact of WIL projects, two different (qualitative and quantitative) and discipline-specific (Marketing and HRM) research studies collaborated to conduct interdisciplinary comparisons on their data.

The qualitative and quantitative methodologies and results are presented separately, before presenting a triangulated discussion of significant findings. This section presents the 
research paradigm, design, sampling, participants, procedure, analysis and ethical considerations for each of the qualitative (Marketing) and quantitative (HRM) WIL studies conducted.

\section{Qualitative marketing study}

The Marketing project that is discussed in this article is a WIL project whereby National Diploma: Marketing students have to sell products for companies that are affiliated to the Direct Selling Association (DSA) of South Africa. Students are taught the subject theory in the Personal Selling and Sales Management classes and are expected to apply this knowledge in the real world by achieving a set sales target. This project is referred to as the DSA-UJ Project (Wait 2014).

To determine the impact of the DSA-UJ Project on students' careers, the views of students who successfully passed the DSA-UJ WIL Project were measured. This part of the article made use of a qualitative research design and used two group interviews that were analysed by using deductive content analysis. Petzer $(2011,32)$ opines that exploratory research is usually linked to qualitative research. Deductive content analysis is used when the structure of analysis is operationalised on the basis of previous knowledge and the purpose of the study is theory testing. A deductive approach is based on a theory or model and therefore moves from the general to the specific. Elo $(2007,109)$ continues and states that deductive content analysis includes three phases namely, preparation, organising and reporting. However, despite this, there are no systematic rules for analysing data and the key feature of all content analysis is that many words of text are classified into smaller categories.

Preparation phase: In this phase the researcher must consider the following: what to analyse, in what detail, sampling matters, and the unit of analysis (Elo 2007, 109). For the purpose of this study the researchers wanted to test opinions about the impact of the DSA-UJ Project on students' careers and the participants were randomly selected from a list of students who had successfully completed the DSA-UJ Project. Two group interviews were held with six students each. Berndt and Petzer $(2011,45)$ state that qualitative research assists in understanding the background to the research problem, and this type of research involves fewer participants and emphasises that the quality of the information is important. Elo $(2007,109)$ states that the most suitable unit of analysis for content analysis research is a whole interview that is large enough to be considered as a whole, and small enough to be kept in mind as a context for meaning unit during the analysis process. The researcher also acted as the interviewer and led the group interviews according to a predetermined topic list related to the 
skills and career prospects of the participants. The meetings were recorder and transcribed. The data from the transcribed meetings was then analysed using the qualitative content analysis, then using predetermined codes method.

The next phase is the analytical process whereby the researcher learns 'what is going on?', and tries to make sense of the data. (Elo 2007, 109). Berndt and Petzer (2011, 84) postulates that qualitative methods are defined in trying to develop an understanding of how participants experience a particular occurrence. The researcher wants to understand the participants thought processes and motivation, and is responsible for interpreting the participants' experiences (Berndt and Petzer 2011, 85). Elo (2007, 111) continues and suggests that deductive content analysis be used for testing categories, concepts, models and hypotheses.

The next step in qualitative content analysis is to develop a categorisation matrix (Elo 2007, 110). Categories should be defined in ways that will be understandable to others, and a good example is to use operational definitions that are clear and specific. For the purpose of this study, the following data categories were created: benefits of WIL to students, student placement, and increased opportunities for career prospects. After the categorisation matrix has been developed, all the data is reviewed for content and coded for correspondence to the identified categories (Elo 2007, 107).

The previous section presented the methodology of the qualitative Marketing study. The next section presents the methodology of the quantitative HRM study.

\section{Quantitative HRM study}

The research paradigm of the HRM study is grounded in a post-positivism philosophy (Zammito 2004; Hamlin 2015). The ontological and epistemological approach implies that even objective research is a real, live, interactive process where the gathering of data and the analysis and interpretation of results are somewhat influenced by both researcher and participants (Zammito 2004; Hamlin 2015; Heppner et al. 2015). The research design is a quantitative survey questionnaire commonly used to gather data on multiple factors, from a large sample, in order to justify conclusions and make inferences on the larger population (Thomas 2008; Nardi 2015). Convenience and purposive sampling (Tongco 2007) was used to select research participants from the student population. Third-year HRM Diploma students who were targeted for the WIL experience in their HRM module were invited as participants. Of the 103 students who completed the questionnaire, 100 questionnaires were considered to be valid and are included in the analysis. This study achieved an excellent response rate of 97 per cent.

The data gathering procedure entailed distributing a self-administered questionnaire for 
completion during lecture time. Participants were invited to participate in the research study voluntarily and were assured that all data will be used for research purposes only. Participants completed the questionnaire by writing down their responses to open-ended questions and rating their responses on a Likert scale of highly disappointing (1), disappointing (2), average (3), rewarding (4), or highly rewarding (5). Section A of the questionnaire captured the biographical data of the participants. Section B captured the organisational and workplace data. Section C requested responses on how students prepared for their WIL placement and experience. Section D requested information on student WIL experience itself. In Section E of the questionnaire, students reported on how they experienced completing and compiling their POE for assessment. Section F evaluated how students experienced the HRM WIL implementation itself. Although the quantitative study gathered data on various topics related to the WIL project as part of the Review Phase of the HRM WIL Partnership Model (Govender and Taylor 2015), this article only reports on a part of the larger study. The aspects of the questionnaire that related directly to the benefits of WIL, WIL placement and career prospects related to the student WIL experience were analysed and presented in this article.

The data was analysed using exploratory and descriptive research techniques (Henson and Roberts 2006). The quantitative results of this article present the frequency statistics and the open-ended responses to the benefits of the WIL experience to students, the rewards of selfplacement to students, and career prospect choices of students. The data was captured onto an Excel spreadsheet and uploaded into the SPSS software programme for frequency, factor and reliability testing.

The ethical considerations of the research assured participants of confidentiality, anonymity and the gathering of data for research purposes only. No participant was treated unfairly, unjustly or victimised as a result of this study.

\section{RESULTS}

This section will present the Marketing and Human Resources results.

\section{Qualitative marketing results}

\section{Biographical data}

The biographical data revealed that the majority (two thirds) of the participants were younger than 20 years. The majority of the participants were female (57\%) and 43 per cent were male. 


\section{WIL benefits}

Participants in this study indicated that they had benefited greatly from the DSA-UJ Project in various ways. The referencing system that will be used with direct quotations will be Group 1 (G1) and Group 2 (G2). The participants felt that the Project was challenging but enjoyable, 'I treated the Project like a business and it forced me to communicate, something that may not have happened otherwise' (G2). 'The Project gave me confidence and I was able to approach strangers' (G1).

The participants felt that the project added to their sales abilities, clerical abilities, managerial skills and office skills, 'You put into practice what you learn in the classroom’ (G1). 'It gave me sales experience’ (G2).

\section{Self-placement}

With the DSA-UJ Project all the students (100\%) chose their own company during an expo of participating companies, therefore 100 per cent self-placement. The students overall enjoyed the idea of selecting their own company, 'I fit the company I chose' (G1). 'I could rise to the challenge and extend my thinking' (G2).

However, many of the students also felt that many times they did not know whom to complain to if things went wrong, 'I did not know whom to complain to in the company if I had a query' (G1). 'Sometimes if there were delivery problems or product outages the company didn’t take us seriously' (G2).

\section{Career prospects}

The vast majority of respondents thought that the DSA-UJ Project advanced their career prospects, 'It removed the doubt I had in myself about my career' (G1). 'It gave me first-hand experience of the sales industry and the work environment' (G2). 'It helped me build my CV' (G2).

\section{Quantitative HRM results}

\section{Biographical data}

The biographical data revealed that the majority of the participants were between the ages of 20-27 years. In this age group, 14 per cent were 24 years old, while the majority of the students, (33\%) were 23 years old; with 28 per cent at 22 years, and 13 per cent were 21 years old. The majority of participants, (65\%) were female and 34 per cent were male. 


\section{WIL benefits}

Section D of the survey questionnaire requested students to rate their responses to statements on the benefits of their WIL experience as highly rewarding, rewarding, average, disappointing or highly disappointing. The analysis revealed that 82 per cent of the students rated their entire WIL experience as rewarding, with 53 per cent stating that their experience was highly rewarding. While 10 per cent rated the entire WIL experience as average, 5 per cent found the experience to be disappointing.

Furthermore, the study revealed that the WIL experience has significant benefits to students in the areas of meeting managers, other staff, induction, tasks and theory-practical linkages. Students rated the following areas as rewarding: first meeting with supervisor and/or mentor (91\%); first meeting with staff (85\%); first meeting with manager/s (75\%); orientation and/or induction (81\%); allocation of tasks and responsibilities (64\%); and alignment to module-specific outcomes (55\%).

Moreover, when students were requested to complete the open-ended questions in Section F, students described the benefits of their WIL experience in the following slogans:

Change (your) thoughts and (the) world.

Paving (my) way to success.

(Way) to a brighter future.

Hard work pays and don’t be afraid to learn.

Love what you do and (you) will do it right.

Sky is indeed the limit!' so 'ok, what's next?

\section{Self placement}

Question 5 of Section B of the survey questionnaire requested students to respond to whether they found placement themselves or were assisted by the university WIL Coordinator, or found a workplace via some other means. The results reveal that 87 per cent of the students found their own workplace to gain their WIL experience, resulting in a majority of the students engaging in self-placement. Although no responses were recorded for institutional placement, the 11 per cent who reported using other placement means included the name of the WIL Coordinator as part of their responses, together with placement via peer and community assistance. While 63 per cent of the students reported that finding an organisation to gain their WIL experience was rewarding, 19 per cent rated the experience as disappointing, and 17 per cent rated finding their own organisation as average. On the additional variable that measured confirming their placement after they had found their organisation, 73 per cent of the students 
rated the experience as rewarding. While 19 per cent of the students rated that confirming their placement was an average experience, 6 per cent rated it as disappointing.

The student slogans that best describe their placement experience as captured by this quantitative study are as follows:

Embrace yourself (for self-placement)!

(Self-placement) bring(s) the workplace to students (versus placing students)

Early birds catches (the) fattest worms

'(Forced) out of comfort zone' but 'fun way to learn' in order to 'meet the real world'

Self-placement is 'For (my) greater good'.

Furthermore, in support of the self-placement approach, the study found that the time students spent gaining their WIL experience far exceeded the minimum prescribed timespan of 20 hours over 1 week. A majority of 56 per cent of the students served 40 hours in the workplace, while 24 per cent served for between 41 to 50 hours. Significantly, a further 7 per cent of students spent over 50 hours in the workplace for their WIL experience.

\section{Career prospects}

On the question of whether students would consider the organization in which they served their WIL experience for further career prospects after graduation, 68 per cent of the students responded that they would, and 13 per cent said that they would not. The reasons for selecting the organisation as a potential future employer are as follows:

helpful, employees united, supportive, friendly, welcoming, enjoyed working in organisation, worked well under pressure, worked well with, improved skills, challenging, has vacancies, personality studies, future development plans, aligned to career objectives, field workaholic, good organisation goals, positive culture, interesting, inspiring.

Those students who did not consider the organisation as a potential for future career prospects cited the following reasons for their negative response:

full of critics, lack of resources, environment not pleasing, boring, too much politics, retail industry not for me, employees not treated well, too much workload, not relevant.

On the question of whether students would recommend the organization from which they gained their WIL experience to future HRM graduating students, 68 per cent responded positively and 13 per cent negatively. The reasons cited by students for recommending the organisation are as follows: 
students were treated well, mentor was helpful, mentors are professional, assisted students, staff supportive, better place to learn, HR needs fresh people, good communication, industry is insightful, meet different people, growth opportunity.

The reasons for not recommending the organisation for future career prospects of future HRM graduating students are as follows:

focus (is) on engineering, lacked HR support, (they were) unprepared for students, limited HR, little experience (in HRM).

Student slogans that best describe the impact of their WIL experience on their future career prospects are as follows:

'Everything is possible' when 'building careers', there are 'unlimited opportunities' for 'entry to workplace' to gain 'practical HR' and realise that 'HR is possible!'

'Key to future workplace!'

'Keep real and resolve disputes/gain information' as 'work experience is a prerequisite' and 'practise makes perfect', especially if you put 'knowledge to work' and 'experience the world of workers'.

An overall bird's eye-view of the responses of students in the quantitative survey is that the WIL project improved their 'strategic thinking' and it encouraged students to 'WIL yourself', 'believe in me' and be 'managers for a week', while having a 'fantastic', 'excellent', 'enriching' and 'fun' experience.

\section{DISCUSSION}

This section of the article reports on the triangulated interpretation and sense-making of the interdisciplinary, mixed mode analysis of the results of both the independent, discipline specific qualitative and quantitative studies. A comparative analysis of both studies allowed the researchers to arrive at similar and profoundly significant findings. These triangulated findings will be discussed for each of the research objectives as follows: benefits of WIL projects, WIL self-placemen, and career prospect benefits.

\section{Biographical results}

In both studies females are in the majority (Marketing 57\%; HRM 66\%). These findings are aligned to the demographical statistics of the country (SA 2015). The majority of the students in the HRM study were much older (20-27 years), while in the Marketing study the majority of the students were younger than 20 years. This finding is attributed to the fact that the 
Marketing students were in their second year of study compared to the HRM students who were in their final year of study.

\section{Identified benefits of WIL projects}

The findings of both the Marketing and HRM studies indicated that the majority of the students benefited from their WIL experiences. Overall, the students in both these studies indicated that they had rewarding experiences and have acquired enhanced knowledge and skills needed for their separate disciplines.

These findings are in line with similar studies conducted by Orrell (2004), McLennan and Keating (2008), Freudenberg, Brimble and Vyvyan (2010) and Cooper, Colin and Gordon (2010) who state that students are to derive several benefits from WIL experiences, namely, development of relevant discipline specific skills, personal attributes, and communicative abilities.

\section{Rewards of self-placement}

The vast majority of the students in both the Marketing (100\%) and HRM (87\%) studies indicated that they found their own placement for serving their WIL experiences. Furthermore, in both studies students expressed that they enjoyed the self-placement technique, even though they were initially nervous about this approach.

These findings are in line with the work of Gribble et al. (2014) that states that the most significant influence of a student's future career is WIL placement. This is also in line with the findings of Govender and Taylor (2015) who emphasise self-placement as an essential tool for empowering students from the beginning of the WIL project.

\section{Choices for future career prospects}

The vast majority of students in both studies felt that their respective WIL projects advanced their career prospects enormously and may have removed any doubt about their choice of disciplines. Some students indicated that they worked very well in their organisations of choice due to the fact that what they had studied in class, was now made relevant and practical by their WIL experience.

These findings are in line with Gamble, Patrick and Peach (2010) and Gribble et al. (2014) who posit that critical thinking and intellectual reflection occur when cognitive abilities are tested and tried in an authentic workplace environment. 


\section{CONCLUSION}

Many articles abound on WIL benefits, as was evident in the literature review of this article. Research of WIL projects is normally discipline specific, and transdisciplinary WIL research is scarce. This article provides insight into a transdisciplinary approach to comparing, analysing and triangulating two different disciplinary specific WIL studies. This article contributed to the knowledge that although silo-based WIL research studies flourish, transdisciplinary WIL triangulation papers which have many common findings, are still in their infancy.

\section{REFERENCES}

Aldridge, R., R. A. Callahan, Y. Chen and S. R. Wade. 2015. Income tax preparation assistance service learning program: A multidimensional assessment. Journal of Education for Business 90(6): 287295.

Berndt, A. and D. Petzer. (Eds.). 2011. Marketing research. Cape Town: Heinemann.

Betts, K. 2009. Optimising learning simulation to support a quinary career development model. AsiaPacific Journal of Cooperative Education 10(2): 99-119.

Brundiers, K., A. Wiek and C. L. Redman. 2010. Real-world learning opportunities in sustainability: From classroom into the real world. International Journal of Sustainability in Higher Education 11(4): 308-324.

Coll, R. 2007. Learning science and technology through cooperative education. Asia-Pacific Journal of Cooperative Education 8(2): 137-147.

Coll, R. K. and K. E. Zegwaard. 2006. Perceptions of desirable graduate competencies for science and technology new graduates. Research in Science \& Technological Education 20(1): 29-58.

Cooper, S., C. Bottomley and J. Gordon. 2004. Stepping out of the classroom and up the ladder of learning: An experiential learning approach to entrepreneurship education. Industry and Higher Education 18(1): 11-22.

Cooper, L., J. Orrell and M. Bowden. 2010 Work integrated learning: A guide to effective practice. Routledge, NY.

Elo, S. 2007. The qualitative content analysis process. Journal of Advanced Nursing 62(1): 107-115.

Freudenberg, B., M. Brimble and V. Vyvyan. 2010. The penny drops: Can Work Integrated Learning improve student's learning? E-Journal of Business Education \& Scholarship of Teaching 4(1): 42-61.

Gamble, N., C. Patrick and D. Peach. 2010. Internationalising work-integrated learning: Creating global citizens to meet the economic crisis and the skills shortage. Higher Education Research \& Development 29(5): 535-546.

Govender, C. M. and S. Taylor. 2015. A work integrated learning partnership model for higher education graduates to gain employment. South African Review of Sociology 46(2): 43-59.

Gribble, N., A. Dender, E. Lawrence, K. Manning and T. Falkmer. 2014. International WIL placements: Their influence on student professional development, personal growth and cultural competence. Asia-Pacific Journal of Cooperative Education 15(2): 107-117.

Hamlin, B. 2015. Paradigms, philosophical prisms and pragmatism in HRD research. Handbook of research methods on human resource development, 13.

Harrison, R. L. and T. M. Reilly. 2011. Mixed methods designs in marketing research. Qualitative Market Research: An International Journal 14(1): 7-26.

Henson, R. K. and J. K. Roberts. 2006. Use of exploratory factor analysis in published research common errors and some comment on improved practice. Educational and Psychological Measurement 
66(3): 393-416.

Heppner, P., B. Wampold, J. Owen, M. Thompson and K. Wang. 2015. Research design in counseling. Cengage Learning.

Holdsworth, A., K. Watty and M. Davies. 2009. Developing capstone experiences. Centre for the Study of Higher Education, University of Melbourne.

Ishisaka, H., N. E. Farwell, S. S. L. Song and E. S. Uehara. 2004. Teaching notes, partnership for integrated community-based learning: A social work communitycampus collaboration. Journal of Social Work Education 40(2).

Leech, N. L. and A. J. Onwuegbuzie. 2007. An array of qualitative analysis tools: A call for data analysis triangulation. School Psychology Quarterly 22: 557-584. doi:10.1037/1045-3830.22.4.557.

Matoti, N., E. K. Junqueira, R. J. Odora. 2011. A comparative study of pre-service teachers’ self-efficacy beliefs before and after work integrated learning. South African Journal of Higher Education 25(6): 1140-1177.

Mcllveen, P. 2011. Developing learning professionals. SpringerLink. Australia.

McLennan, B. and S. Keating. 2008. Work-integrated learning (WIL) in Australian universities: The challenges of mainstreaming WIL. In ALTC NAGCAS National Symposium.

Nardi, P. M. 2015. Doing survey research. Routledge.

Orrell, J. 2004. Work-integrated learning programmes: Management and educational quality. In Proceedings of the Australian Universities Quality Forum,1-5. AUQA Occasional Publication.

Powell, S., I. Tindal and R. Millwood. 2008. Personalized learning and the ultraversity experience. Interactive Learning Environments 16(1): 63-81.

Reiche, B. S., A. W. Harzing, M. L. Kraimer. 2009. The role of international assignees' social capital in creating inter-unit intellectual capital: A cross-level model. Journal of International Business Studies 40(3): 509-526.

Reiche, B. S., M. L. Kraimer and A. W. Harzing. 2011. Why do international assignees stay and quest: An organisational embeddedness perspective. Journal of International Business Studies 42(2): 521-544.

South Africa. 2011. National Development Plan: Vision for 2030. Pretoria: Government Printer.

Saunders, M., P. Lewis and A. Thornhill. 2007. Research Methods for Business Studies. $4^{\text {th }}$ Edition. Harlow: Prentice Hall.

Thomas, Jessie. 2008. Quantitative method. Community in Higher Education. Spring Arbor University.

Tongco, Maria Dolores C. 2007. Purposive sampling as a tool for informant selection. Ethnobotany Journal 5: 147-158.

Valkanos, E. et al. 2007. Experiential learning - its place in in-house education and training. Development and Learning Organisations 21(5): 21-23.

Wait, M. 2014. A marketing work-integrated-learning project: A working model. South African Journal of Higher Education 28(5): 1680-1693.

Walmsley, A., R. Thomas and S. Jameson. 2006. Surprise and sense making: Undergraduate placement experiences in SMEs. Education + Training 48(5): 360-372.

Zammito, John H. 2004. A nice derangement of epistemes: Post-positivism in the study of science from Quine to Latour, 10-21. University of Chicago Press. 